\title{
ERECTILE DYSFUNCTION AND COVID-19: A CASE REPORT
}

\author{
Gembong Satria Mahardhika $^{1 *}$, Nastiti Maharani ${ }^{1}$, Theodore Dharma Tedjamartono ${ }^{1}$, Efriadi Ismail $^{1}$ \\ ${ }^{1}$ Rumah Sakit Darurat Wisma Atlet, DKI Jakarta, Indonesia \\ *Correspondence email: mahardhika.gembong@gmail.com
}

\begin{abstract}
Coronavirus Disease-2019 (COVID-19) infection is suspected to affect sexual behavior and function of sexual. COVID-19 can cause penile vascular damage that leads to erectile dysfunction (ED). This problem is one of the most common sexual problems in men, with a percentage of $13-28 \%$ at the age of 40-80 years and the incidence increases with age. Currently, there is no data on the effect of COVID19 on sexual behavior. There was one case of COVID-19 with erectile dysfunction treated at COVID19 Emergency Hospital, Kemayoran Athlete Village. Erectile dysfunction is influenced by several factors, including psychogenic and neurogenic factors and infection. The diagnosis of erectile dysfunction was determined based on history taking and physical examination using the standard questionnaire (IIEF-5/International index of erectile function-5). A further study is needed to exclude a particular cause and the management of erectile dysfunction, which can be determined based on the etiology.
\end{abstract}

Keywords: SARS-CoV-2; Impotence; Sexual dysfunction.

\section{INTRODUCTION}

Erectile dysfunction occurs due to the sexual response blockage on the spinal nerve that is mediated by the neurotransmitter serotonin. Therefore, it is failed to initiate (neurogenic, psychogenic, endocrinologic), fill (atherogenic), accommodate, or maintain (corporal Veno-occlusive dysfunction) penetrating erection and erectile relaxation (priapism). ${ }^{1}$ Erectile dysfunction occurs in men with a percentage of $13-28 \%$ at the age of 40-80 years. Several etiologies are stated as the cause of erectile dysfunction, such as vasculogenic, psychogenic, and neurogenic factors, as well as infection. This case rarely takes place and is rarely published. On the other hand, the pathophysiology of erectile dysfunction can develop through numerous mechanisms. Therefore, this case report is organized by presenting some hypotheses regarding erectile dysfunction in a COVID-19 patient.

\section{CASE ILLUSTRATION}

A 55-year-old man complained of anosmia 13 days before being treated at COVID-19 Emergency Hospital, Kemayoran Athlete Village, Jakarta. When the patient woke up, he experienced anosmia, followed by the inability to erect. The result from physical examination showed that his vital signs and general status were normal. It was found that the cremasteric reflex was positive from the local status examination. The result of COVID-19 RT-PCR (ReverseTranscriptase Polymerase Chain Reaction) was positive. Total blood examination and blood chemical profile, such as total cholesterol level, triglyceride, and fasting blood glucose, were found to be at normal rates. The patient got first-line COVID-19 therapy in accordance with COVID-19 protocol consisted of Azithromycin 1x500mg for five days, Oseltamivir $2 \times 75 \mathrm{mg}$ for seven days, Zinc $1 \times 20 \mathrm{mg}$, as well as micronutrient supplements containing Vit B1 of $15 \mathrm{mg}$, Vit 
B2 of $10 \mathrm{mg}$, Vit B6 of $5 \mathrm{mg}$, Ca Pantothenate of $20 \mathrm{mg}$, and Nicotinamide of 50mg 2x1 a day. During the treatment, the patient was unable to erect and fall asleep. The patient was admitted for worrying about his condition and longing for the family. The patient received Clozapine 1x12.5 mg therapy. Within the observation, the patient's sleep habit was getting better. After getting treatment for 24 days, the patient was able to erect when waking up in the morning. The anosmia was getting better as well. The patient was finally able to move and socialize. Later, a swab test was once again done after treatment, which resulted in a negative RT-PCR so that the patient could be discharged.

\section{DISCUSSION}

Erectile dysfunction is the inability to maintain erectile function in achieving satisfying sexual activity. ${ }^{2}$ Erectile dysfunction diagnosis is established comprehensively, not only based on specific events. ${ }^{3}$ After the patient was found to experience erectile dysfunction symptoms, indepth anamnesis was done regarding other histories, chronic diseases, certain drug usage, or psychosocial problems. In this case, the erectile dysfunction diagnosis was made based on the International Index of Erectile Function-5 (IIEF-5), which resulted in a score of 11 , which means moderate dysfunction. Erectile dysfunction occurs due to neurologic, endocrine, arthritogenic, venogenic, psychogenic, pharmacogenic, or iatrogenic abnormalities. ${ }^{1}$ Therefore, physical and supporting examinations were needed to remove other etiologies, such as endocrine, metabolic, and cardiovascular diseases.

Many cardiovascular disease risk factors, particularly age, lifestyle, obesity, smoking habit, hypercholesterolemia, metabolic syndrome, insulin resistance, hypertension, and diabetes mellitus, affect erectile dysfunction. Therefore, early evaluation of erectile dysfunction had to distinguish erectile dysfunction vasculogenic from other etiologies. Findings from the analyzed case were used to execute various possible etiologies that could happen. In this case, it was found that the patient was an adult without a smoking history who had a job as a tennis coach. Other disease factors such as metabolic syndrome and diabetes were also not found.

Erectile dysfunction in general, basic pathophysiology, and cardiovascular disease were included in endothelial dysfunction, inflammation, and low testosterone level. Endothelial dysfunction develops due to the decrease in oxide nitrite synthesis and atherosclerosis that causes damage to blood flow that functions for erection. Erectile dysfunction associated with the calcification of the coronary arteries in the heart forms an atherosclerotic plaque that will be linked to cardiovascular disease. ${ }^{4,5}$ The occurrence of erectile dysfunction is correlated with endothelial function damage, specifically affecting the vasodilatory function of the brachial artery. ${ }^{7}$ The role of infection incidents can be considered, especially in the formation of atherosclerosis associated with erectile dysfunction and cardiovascular disease. $^{6}$

Other factors of psychogenic can be obtained when there is sudden onset erectile dysfunction, decreased libido, and loss of erectile function in the morning. ${ }^{7}$ Psychogenic factors include worry, trauma due to sexual experience, loss of interest, and inadequate communication with a partner. In this case, it was found that the patient was worried about the health and family problems caused by COVID-19.

Regarding sleep-related erection (SRE), erection can occur without stimulation when one is asleep, specifically when entering Rapid Eye Movement (REM) phase. Lateral Preoptic Area (LPOA) controls this mechanism, where lesions on bilateral preoptic area cause the absence of SRE. ${ }^{8} \mathrm{SRE}$ is used to help the erectile dysfunction diagnosis as a result of psychogenic factor. Normal SRE is assumed to have a relation with normal erectile physiology. Meanwhile, on erectile dysfunction caused by other etiologies, SRE function is damaged. In this case, the patient's inability to erect was also 
found all the time, including when he was asleep and after waking up.

With COVID-19 infection, erectile dysfunction, in this case, needs to be explored thoroughly. Coronavirus infection is related to neuropsychiatric disorder on Severe Acute Respiratory Syndrome (SARS) and Middle East Respiratory Syndrome (MERS). It was found that there is a direct infection on Central Nervous System (CNS) or indirect infection through the immune response mechanism.

A study conducted by Desforges et al. ${ }^{14}$ also show that coronavirus can cause psychiatric symptoms due to infiltration in the brain that can occur in SARS-CoV-2. ${ }^{11}$ In COVID-19 infection, cytokine storm is suspected to be involved in immune response related to neuroinflammation; where cytokine disturbance, especially IL-1B, IL-6, IL-10, IFN-y, TNF-a, and transforming growth factor-B (TGF-B) are related to the psychiatric disorder. ${ }^{12}$ Neuro disorder on SARS-CoV-2 infection like anosmia and ageusia causes a hypothesis that this infection is presumably spread to CNS. ${ }^{13}$ Other relevant studies also show that SARS-CoV-2 is present in the examination of Cerebrospinal Fluid (CSF). ${ }^{14}$ Further research is needed to find psychiatric disorders as the manifestation of CNS involvement in COVID-19 infection.

In the patient, anosmia and erectile dysfunction symptoms were found simultaneously before the patient was infected with the SARS-CoV-2 virus. Overall, there was a neurologic symptom that often occurred to a patient with a COVID-19 infection, in which anosmia can be found at the beginning of COVID-19. The SARSCoV-2 virus enters the cell through Angiotensin-Converting Enzyme-2 (ACE-2) receptor. Spike protein related to ACE-2 receptor and can be completed with some protease enzymes (TMPRSS2 and furin) that are basically expressed by positive cells on ACE-2. ${ }^{15,16,17}$ There were receptors in the form of SARS-CoV-2 and coronavirusassociated factors and receptors (SCARFs) which have roles in responding to virus ties with a system, specifically on sequencing or high throughput datasets. ${ }^{18}$ Anosmia symptom is based on ACE-2 expression on olfactory epithelium system.$^{19}$

A molecular mechanism that is able to explain neurological disorders requires more explanation by further research. There is a chance of dataset sorting process or sequencing from RNA causing ACE-2 to be expressed in dorsal root ganglion from a neurological disorder. A single-cell sequencing experiment from the dorsal root ganglion in mice has shown that there is a low neurologic expression of ACE-2 that also expresses Mrgprd and Nppb gen. ${ }^{20}$ MrgprD is a selective gene expressed by nociceptive structures in free nerve endings such as the skin, cornea, and luminal organs, namely bowels and meninges. ${ }^{21,22,23}$

According to Shiers et al., cellular expression of SARS-CoV-2 is associated with ACE-2 mRNA in nerve cells expressing calcitonin-gene-related peptide (CALCA) and $\mathrm{P} 2 \mathrm{X}$ purigenic ion channel type 3 receptor gene (P2RX3). ${ }^{24}$ CALCA and P3RX3 genes are known to illustrate the subpopulation nociceptors in the dorsal root ganglion of mice. ACE-2 mRNA can be found in 19.8$25.4 \%$ of the sensory nerve cells. The majority of ACE-2 expression can also be found in the nociceptive structure of a human's dorsal root ganglion..$^{25}$

The occurrence of erectile is related to the innervation of the penis for both the autonomic nerve (sympathies and parasympathies) and somatic systems (sensory and motoric). Penile nerves originate from the spinal cord and peripheral ganglion. Sympathetic and parasympathetic nerves merge into cavernous nerves, which will innervate the corpora cavernosa, corpora spongiosa, causing vasodilatation and then erection. Somatic nerves are related to the process of musculus bulbocavernosus and ischiocavernosus contractions. Thus, an erection occurs. $^{25}$

Infection can affect the central nervous system, including neuropsychiatric disorders. One of the infection factors itself can also cause abnormality in the reproduction system that includes erectile dysfunction. The etiology factor of the infection that is directly 
related to erectile dysfunction is assumed to appear. Virus infection, either directly or indirectly, can cause erectile dysfunction. It works directly on the inflammation process that is crucial to atherosclerosis formation. Virus infection causes an increase in inflammatory markers, such as CRP, IL-6, IL$1 b$, TNF- $\alpha$, intercellular adhesion molecules, and adhesion molecules on vascular cells that connect to erectile dysfunction. ${ }^{26,27}$

COVID-19 infection is caused by the association between the dorsal root ganglion ACE-2 receptor with the virus itself, which then causes structural damage. This damage can irritate nerve stimulus function that is associated with erection on the sacral nerve segment. Therefore, there is a disturbance in pudendal nerves (S2-S4). Damage on the sacrum has a role in erectile dysfunction. Erectile dysfunction in COVID-19 patients also can be caused by the impairment of blood vessels in the penis. ${ }^{28,29}$

Based on this case report, further study is needed to determine factors that connect with reproduction system disorder, such as erectile dysfunction in virus infection, including COVID-19. The relationship between one etiology to another may also be found by an in-depth study.

\section{CONCLUSION}

Erectile dysfunction in COVID-19 infection can be caused by many factors, including psychogenic factors and infection. Up to this moment, reports and scientific studies about COVID-19 are still limited. Therefore, controlling and further studies are required regarding the rise of erectile dysfunction. Therapy given to the patient is based on the COVID-19 therapeutic regimen that is still under further research. Psychologic, metabolic, vasculogenic, and other supporting factors have become important points to be considered as they play a role in predicting erectile dysfunction. Factors regarding erectile dysfunction in COVID-19 cannot be assessed from a certain side only. Consequently, further research is needed to answer the challenges and existed hypotheses.

\section{REFERENCES}

1. Leung A, Christ G, Melman A. Physiology of Penile Erection and Pathophysiology of Erectile Dysfunction. Atlas of Male Sexual Dysfunction. 2004;:1-25.

2. Lewis RW, Fugl-Meyer KS, Corona G, Hayes RD, Laumann EO, Moreira ED, et al. Definitions/epidemiology/risk factors for sexual dysfunction. J Sex Med. 2010;7(4 PART 2):1598-607.

3. Irwin GM. Erectile Dysfunction. Prim Care - Clin Off Pract [Internet]. 2019;46(2):249-55. Available from: https://doi.org/10.1016/j.pop.2019.02.00 6

4. Montorsi F, Briganti A, Salonia A, Rigatti P, Margonato A, Macchi A, et al. Erectile dysfunction prevalence, time of onset and association with risk factors in 300 consecutive patients with acute chest pain and angiographically documented coronary artery disease. Eur Urol. 2003;44(3):360-5.

5. Montorsi P, Ravagnani PM, Galli S, Briganti A, Salonia A, Dehò F, et al. Association between erectile dysfunction and coronary artery disease: A case report study. J Sex Med. 2005;2(4):575-82.

6. Montorsi P, Ravagnani PM, Galli S, Rotatori F, Veglia F, Briganti A, et al. Association between erectile dysfunction and coronary artery disease. Role of coronary clinical presentation and extent of coronary vessels involvement: The COBRA trial. Eur Heart J. 2006;27(22):2632-9.

7. Chiurlia E, D'Amico R, Ratti C, Granata AR, Romagnoli R, Modena MG. Subclinical coronary artery atherosclerosis in patients with erectile dysfunction. J Am Coll Cardiol. 2005;46(8):1503-6.

8. Vlachopoulos C, Rokkas K, Ioakeimidis N, Aggeli C, Michaelides A, Roussakis $\mathrm{G}$, et al. Prevalence of asymptomatic coronary artery disease in men with vasculogenic erectile dysfunction: A prospective angiographic study. Eur Urol. 2005;48(6):996-1003. 
9. Huang CC, Chan WL, Chen YC, Chen TJ, Chung CM, Huang PH, et al. Herpes simplex virus infection and erectile dysfunction: a nationwide populationbased study. Andrology. 2013;1(2):2404.

10. Farre JM, Fora F, Lasheras MG. Specific aspects of erectile dysfunction in psychiatry. Int $\mathrm{J}$ Impot Res. 2004;16(SUPPL. 2):46-9.

11. Schmidt MH, Schmidt HS. Sleep-related erections: Neural mechanisms and clinical significance. Curr Neurol Neurosci Rep. 2004;4(2):170-8.

12. Rogers J, Chesney E, Oliver D, Pollak T, McGuire P, Fusar-Poli P et al. Psychiatric and neuropsychiatric presentations associated with severe coronavirus infections: a systematic review and metaanalysis with comparison to the COVID19 pandemic. The Lancet Psychiatry. 2020;7(7):611-627.

13. Wu Y, Xu X, Chen Z, Duan J, Hashimoto $K$, Yang $L$ et al. Nervous system involvement after infection with COVID19 and other coronaviruses. Brain, Behavior, and Immunity. 2020;87:18-22.

14. Desforges M, Le Coupanec A, Dubeau P, Bourgouin A, Lajoie L, Dubé $M$ et al. Human Coronaviruses and Other Respiratory Viruses: Underestimated Opportunistic Pathogens of the Central Nervous System?. Viruses. 2019;12(1):14.

15. Mazza M, De Lorenzo R, Conte C, Poletti S, Vai B, Bollettini I et al. Anxiety and depression in COVID-19 survivors: Role of inflammatory and clinical predictors. Brain, Behavior, and Immunity. 2020;89:594-600.

16. Speth M, Singer-Cornelius T, Oberle M, Gengler I, Brockmeier S, Sedaghat A. Mood, Anxiety and Olfactory Dysfunction in COVID -19: Evidence of Central Nervous System Involvement?. The Laryngoscope. 2020;130(11):25202525.

17. Moriguchi T, Harii N, Goto J, Harada D, Sugawara H, Takamino J et al. A first case of meningitis/encephalitis associated with SARS-Coronavirus-2. International Journal of Infectious Diseases. 2020;94:55-58.

18. Hoffmann $M$, Kleine-Weber $H$, Schroeder S, Krüger $\mathrm{N}$, Herrler $\mathrm{T}$, Erichsen S et al. SARS-CoV-2 Cell Entry Depends on ACE2 and TMPRSS2 and Is Blocked by a Clinically Proven Protease Inhibitor. Cell. 2020;181(2):271-280.e8.

19. Coutard B, Valle C, de Lamballerie X, Canard B, Seidah N, Decroly E. The spike glycoprotein of the new coronavirus 2019-nCoV contains a furinlike cleavage site absent in $\mathrm{CoV}$ of the same clade. Antiviral Research. 2020;176:104742.

20. Ziegler C, Allon S, Nyquist S, Mbano I, Miao V, Tzouanas $C$ et al. SARS-CoV-2 Receptor ACE2 Is an InterferonStimulated Gene in Human Airway Epithelial Cells and Is Detected in Specific Cell Subsets across Tissues. Cell. 2020;181(5):1016-1035.e19.

21. Singh M, Bansal V, Feschotte C. A single-cell RNA expression map of human coronavirus entry factors. 2020;

22. Butowt R, Bilinska K. SARS-CoV-2: Olfaction, Brain Infection, and the Urgent Need for Clinical Samples Allowing Earlier Virus Detection. ACS Chemical Neuroscience. 2020;11(9):1200-1203.

23. Usoskin D, Furlan A, Islam S, Abdo H, Lönnerberg P, Lou D et al. Unbiased classification of sensory neuron types by large-scale single-cell RNA sequencing. Nature Neuroscience. 2014;18(1):145153.

24. Zylka M, Rice F, Anderson D. Topographically Distinct Epidermal Nociceptive Circuits Revealed Sby Axonal Tracers Targeted to Mrgprd. Neuron. 2005;45(1):17-25.

25. Hockley J, Taylor T, Callejo G, Wilbrey A, Gutteridge A, Bach K et al. Single-cell RNAseq reveals seven classes of colonic sensory neuron. Gut. 2018;68(4):633644.

26. Von Buchholtz L, Lam R, Emrick J, Chesler A, Ryba N. Assigning 
transcriptomic class in the trigeminal ganglion using multiplex in situ hybridization and machine learning. 2020.

27. Shiers S, Ray P, Wangzhou A, Tatsui C, Rhines L, Li Y et al. ACE2 expression in human dorsal root ganglion sensory neurons: implications for SARS-CoV-2 virus-induced neurological effects. 2020;

28. Dean R, Lue T. Physiology of Penile Erection and Pathophysiology of Erectile Dysfunction. Urologic Clinics of North America. 2005;32(4):379-395.

29. Vlachopoulos C, Aznaouridis K, Ioakeimidis N, Rokkas K, Vasiliadou C, Alexopoulos $\mathrm{N}$, et al. Unfavourable endothelial and inflammatory state in erectile dysfunction patients with or without coronary artery disease. Eur Heart J. 2006;27(22):2640-8.

30. Eaton CB, Liu YL, Mittleman MA, Miner M, Glasser DB \& Rimm EB. (2007) A retrospective study of the relationship between biomarkers of atherosclerosis and erectile dysfunction in 988 men. Int J Impot Res 19, 218-225.

31. Liu P, Blet A, Smyth D, Li H. The Science Underlying COVID-19. Circulation. 2020;142(1):68-78.

32. Varga Z, Flammer A, Steiger $P$, Haberecker M, Andermatt R, Zinkernagel A et al. Endothelial cell infection and endotheliitis in COVID-19. The Lancet. 2020;395(10234):14171418. 